\title{
Formulation and Pharmacokinetic Evaluation of Controlled-Release Oxybutynin Tablets in Dogs
}

\author{
Joonho Bae ${ }^{1}$ and Jin Woo Park ${ }^{2 *}$ \\ ${ }^{1}$ Amorepacific Corporation R\&D Center, 314-1, Bora-dong, Giheung-gu, Yongin-si, Gyeonggi-do, 446-729, ${ }^{2}$ College of \\ Pharmacy and Natural Medicine Research Institute, Mokpo National University, 1666 Youngsan-ro, Muan-gun, Jeonnam 534- \\ 729, Republic of Korea
}

*For correspondence: Email: jwpark@mokpo.ac.kr; Tel: +82-61-450-2704; Fax: +82-61-450-2689

Received: 27 September 2014

Revised accepted: 27 December 2014

\begin{abstract}
Purpose: To develop and optimize controlled-release (CR) oxybutynin chloride matrix tablets. Methods: Oxybutynin CR tablets were prepared by embedding drug-containing granules into a hydrogel matrix of hydroxypropyl methylcellulose (HPMC). A coating layer was then applied with a mixture of HPMC, ethylcellulose, shellac, and HPMC phthalate. The effect of several formulation variables on in vitro drug release was studied; furthermore, the drug release kinetics of the optimized formulation was evaluated. The in vivo pharmacokinetics of the optimized formulation was compared with those of commercial immediate-release and CR tablets in dogs.

Results: The core tablets exhibited extended release consisting of drug release from the embedded granules through the erodible hydrogel matrix. Release rate was controlled by the amounts of swellingcontrol agent and hydrogel used. The optimized formulation followed zero-order release up to $24 h$ after an initial lag time. Maximum plasma drug concentration for the optimized and commercial CR tablets was $5.90 \pm 1.42$ and $6.47 \pm 3.73 \mathrm{ng} / \mathrm{mL}$, respectively, while the area under the plasma concentrationtime curve was $101.40 \pm 51.41$ and $112.68 \pm 65.89 \mathrm{ng} \cdot \mathrm{h} / \mathrm{mL}$, respectively.

Conclusion: The formulated oxybutynin CR tablets exhibit prolonged drug release, thus rendering it a potentially suitable once-daily oral formulation for improved patient compliance.
\end{abstract}

Keywords: Oxybutynin, Matrix tablet, Hydrogel, Oral controlled-release, Zero-order release, Pharmacokinetics

Tropical Journal of Pharmaceutical Research is indexed by Science Citation Index (SciSearch), Scopus, International Pharmaceutical Abstract, Chemical Abstracts, Embase, Index Copernicus, EBSCO, African Index Medicus, JournalSeek, Journal Citation Reports/Science Edition, Directory of Open Access Journals (DOAJ), African Journal Online, Bioline International, Open-J-Gate and Pharmacy Abstracts

\section{INTRODUCTION}

Forms of drug administration that are capable of controlling drug release have become an important factor in medical treatment with respect to improved treatment effects, reduced side effects, and enhanced convenience for patients [1].

Oxybutynin chloride is an anticholinergic (antimuscarinic) agent that is commonly prescribed to treat symptoms of urge incontinence, urgency, and frequency arising from over-activity of the detrusor muscle (overactive bladder) [2]. However, oxybutynin is usually given at $15 \mathrm{mg} /$ day in divided doses, and dry mouth secondary to its anticholinergic nature is the most commonly cited reason that patients either discontinue oxybutynin treatment or titrate to a lower dose [3]. To overcome these limitations, an extended-release oxybutynin tablet comprising a two-part core tablet surrounded by a semi-permeable membrane with a laser-drilled orifice on the drug-containing side 
of the tablet was developed. Because this delivery system is primarily governed by osmosis, the drug is delivered into the gastrointestinal (GI) tract at a constant and controlled rate over a 24-h period, independent of $\mathrm{pH}$ and $\mathrm{Gl}$ mobility [4]. Although this system can minimize the peak/trough fluctuations in the plasma drug level associated with repeated dosing, disadvantages include the complicated nature of the system, high cost, and restricted drug release sites.

The objective of the present study was to design a controlled-release (CR) oxybutynin form comprising drug-containing granules, granules embedded with an erosive hydrogel matrix core, and a coating layer to provide constant drug release with minimum dependence on $\mathrm{pH}$ or $\mathrm{Gl}$ mobility.

\section{EXPERIMENTAL}

\section{Materials}

Oxybutynin chloride was obtained from Cadila Healthcare, Ltd. (Ankleshwar, India). Hydroxypropyl methylcellulose (HPMC) 4KM CR and ethyl cellulose (EC) were purchased from The Dow Chemical Company (Midland, MI, USA). HPMC $6 \mathrm{cps}$ and HPMC phthalate (HPMCP) were obtained from Shin-Etsu Chemical Co, Ltd (Tokyo, Japan). Copovidone and glyceryl behenate were obtained from BASF (Ludwigshafen, Germany) and Gattefosse (SaintPriest, France), respectively. Croscarmellose sodium was obtained from FMC Biopolymer (Philadelphia, PA, USA). Microcrystalline cellulose was obtained from JRS Pharma $\mathrm{GmbH}$ \& Co. KG (Rosenberg, Germany), and lactose was obtained from DMV International (Veghel, Netherlands). Magnesium stearate was obtained from NOF Corp. (Tokyo, Japan), and shellac was obtained from Colorcon Inc. (Harleysville, PA, USA). The solvents for high-performance liquid chromatography (HPLC) and liquid chromatography/tandem mass spectroscopy
(LC/MS/MS) analyses were obtained from Merck KGaA (Darmstadt, Germany) and Fisher Scientific (Pittsburgh, PA, USA). Ditropan® (OXY-IR, oxybutynin chloride 5-mg plain tablet) and Lyrinel OROS SR® were obtained from Dong Wha Pharm Co, Ltd (Seoul, Republic of Korea) and Janssen Korea, Ltd. (Seoul, Republic of Korea), respectively.

\section{Preparation of CR oxybutynin tablets}

The CR preparation of oxybutynin chloride was formulated by the wet granulation technique using oxybutynin chloride, glyceryl behenate, a binder, a swelling-control agent, hydrogel, and other pharmaceutical excipients. Briefly, oxybutynin chloride, glyceryl behenate, microcrystalline cellulose, and lactose were placed in a high-speed rotation mixer, and copovidone dissolved in water was slowly added with mixing to obtain granules. The granules were then passed through a \#18 mesh screen, dried in a tray drier at $40^{\circ} \mathrm{C}$, and passed again through a \#20 mesh screen. HPMC 4KM CR, copovidone, croscarmellose sodium, and microcrystalline cellulose were added to the screened granules and mixed for $10 \mathrm{~min}$. The resulting mixture was lubricated with magnesium stearate and compressed to obtain core tablets containing $5 \mathrm{mg}$ of oxybutynin chloride using a tablet press (XL-100 unit; KORSCH, Berlin, Germany). The compositions of the core tablets are summarized in Table 1.

Core tablets with the formulation code OXY/CR5 were also coated with a mixture of hydrophilic polymer and hydrophobic or enteric releasemodifying polymers (HPMC $6 \mathrm{cps}$, EC, shellac, and HPMCP, respectively). Table 2 summarizes the components of the coating layer. The coating solutions were prepared with a mixture of ethanol and dichloromethane $(50: 50, v / v)$. The coatings were applied by spray-pan coating in a perforated pan (Hi-Coater; Freund, Saarland, Germany) until the coating constituted $10 \%$ of the core tablet weight.

Table 1: Composition of oxybutynin controlled-release core tablets

\begin{tabular}{|c|c|c|c|c|c|c|c|}
\hline Ingredient (mg/tablet) & $\begin{array}{c}\text { OXY/C } \\
\text { R1 }\end{array}$ & $\begin{array}{c}\text { OXY/C } \\
\text { R2 }\end{array}$ & $\begin{array}{c}\text { OXYIC } \\
\text { R3 }\end{array}$ & $\begin{array}{c}\text { OXY/C } \\
\text { R4 }\end{array}$ & $\begin{array}{c}\text { OXY/C } \\
\text { R5 }\end{array}$ & $\begin{array}{c}\text { OXY/C } \\
\text { R6 }\end{array}$ & $\begin{array}{c}\text { OXY/C } \\
\text { R7 }\end{array}$ \\
\hline Oxybutynin chloride & 5.0 & 5.0 & 5.0 & 5.0 & 5.0 & 5.0 & 5.0 \\
\hline Glyceryl behenate & 15.0 & 15.0 & 15.0 & 15.0 & 15.0 & 15.0 & 15.0 \\
\hline Microcrystalline cellulose & 59.8 & 56.0 & 51.3 & 89.0 & 70.0 & 51.0 & 32.0 \\
\hline Lactose & 59.8 & 56.0 & 51.2 & 49.6 & 49.6 & 49.6 & 49.6 \\
\hline Copovidone & 9.0 & 9.0 & 9.0 & 9.0 & 9.0 & 9.0 & 9.0 \\
\hline HPMC 4KM CR & 38.0 & 38.0 & 38.0 & 19.0 & 38.0 & 57.0 & 76.0 \\
\hline Croscarmellose sodium & 1.9 & 9.5 & 19 & 1.9 & 1.9 & 1.9 & 1.9 \\
\hline Magnesium stearate & 1.5 & 1.5 & 1.5 & 1.5 & 1.5 & 1.5 & 1.5 \\
\hline Total & 190.0 & 190.0 & 190.0 & 190.0 & 190.0 & 190.0 & 190.0 \\
\hline
\end{tabular}


Table 2: Coating composition of oxybutynin controlled-release tablets

\begin{tabular}{lcccc}
\hline Ingredient (mg/tablet) & $\begin{array}{c}\text { OXYI } \\
\text { CR5C1 }\end{array}$ & $\begin{array}{c}\text { OXYI } \\
\text { CR5C2 }\end{array}$ & $\begin{array}{c}\text { OXYI } \\
\text { CR5C3 }\end{array}$ & $\begin{array}{c}\text { OXYI } \\
\text { CR5C4 }\end{array}$ \\
\hline EC & 1.9 & 3.8 & 5.7 & - \\
HPMC 6 cps & 17.1 & 15.2 & 13.3 & 7.6 \\
Shellac & - & - & - & 4.6 \\
HPMCP & - & - & - & 6.8 \\
\hline
\end{tabular}

\section{In vitro drug release studies}

In vitro drug release from the formulations was evaluated using the United States Pharmacopeia (USP) type 2 method (paddle) at $37^{\circ} \mathrm{C} \pm 0.5^{\circ} \mathrm{C}$ with stirring at $50 \mathrm{rpm}$. The medium was $900 \mathrm{~mL}$ of degassed simulated intestinal fluid (SIFsp, without enzymes). The amount of oxybutynin released to the medium was quantified by HPLC using a $\mu$ Bondapak CN RP column $(10 \mu \mathrm{m}, 3.9 \times$ $300 \mathrm{~mm}$; 20- $\mu \mathrm{L}$ sample injection) with solvent $A$ (mixture of water, methanol, and triethyl amine (3200:800:0.9, v/v/v) at a $\mathrm{pH}$ of 3.5, adjusted with phosphoric acid) and acetonitrile $(80: 20, \mathrm{v} / \mathrm{v})$ as the mobile phase at a flow rate of $2.0 \mathrm{~mL} / \mathrm{min}$. Oxybutynin was detected using a UV detector at $203 \mathrm{~nm}$.

To investigate the effects of the $\mathrm{pH}$ of the release medium and agitation speed, release studies were performed in $900 \mathrm{~mL}$ of water, $0.05 \mathrm{M}$ sodium acetate buffer ( $\mathrm{pH} 4.0)$, and SIFsp (without enzymes) using the USP type 2 method (paddle) at $50 \mathrm{rpm}$ and SIFsp (without enzymes) using the USP type 1 method (rotating basket) at $100 \mathrm{rpm}$. Additionally, in vitro drug-release studies were carried out in $900 \mathrm{~mL}$ of simulated gastric fluid (SGF, without enzymes) for the first $2 \mathrm{~h}$ using the USP type 2 method (paddle) at 50 rpm. The dissolution medium was immediately replaced with $900 \mathrm{~mL}$ of SIFsp (without enzymes) for comparison with the commercialized immediate-release and CR oxybutynin chloride tablets. All samples were analyzed by HPLC.

\section{Pharmacokinetic study in dogs}

The pharmacokinetic study involving dogs was approved by the Animal Care and Use Committee of Chemon Co., Ltd. (Yongin-Si, Gyeonggi-Do, Republic of Korea; Approval date, 01/15/2013; Reference number, MKPHARM-01001). All animal experiments were carried out in accordance with the procedures outlined in the Guide for the Care and Use of Laboratory Animals [5]. Male beagles (6.9 - 8.9 kg; Chemon Co, Ltd, Yongin-Si, Gyeonggi-Do, Republic of Korea) were fasted for $12 \mathrm{~h}$ before drug administration. Three tablets of the test formulation (OXY/CR5C4) or commercial CR formulation (Lyrinel OROS SR), each containing
$5 \mathrm{mg}$ of oxybutynin chloride, were administered orally. A commercial immediate-release formulation (OXY-IR) containing $5 \mathrm{mg}$ of oxybutynin chloride was orally administered to individual animals at 8-h intervals for comparison purposes. After oral administration, blood samples were collected from the jugular vein into tubes containing heparin from 0 (pre-dose) to 24 $\mathrm{h}$ after administration. Additionally, plasma samples were obtained by centrifugation at 3500 $\times \mathrm{g}$ for $10 \mathrm{~min}$ and stored at $-20^{\circ} \mathrm{C}$ until use.

The plasma samples were analyzed for oxybutynin by LC/MS/MS using diazepam as the internal standard (IS). A 1-mL plasma sample spiked with $100 \mu \mathrm{L}$ of the IS solution $(1 \mu \mathrm{g} / \mathrm{mL})$ was added to $0.5 \mathrm{~mL}$ of acetonitrile and $3 \mathrm{~mL}$ of $\mathrm{n}$-hexane and then vortexed for $10 \mathrm{~min}$. After centrifugation at $2000 \times \mathrm{g}$ for $5 \mathrm{~min}$, the organic layer was transferred to a clean glass tube, and $0.3 \mathrm{~mL}$ of $0.1-\mathrm{M}$ hydrochloric acid was added. The sample was then mixed for $10 \mathrm{~min}$, and the two phases were separated by centrifugation at $2000 \times \mathrm{g}$ for $5 \mathrm{~min}$. A total of $20 \mu \mathrm{L}$ of the lower aqueous layer was injected into the LC/MS/MS system for analysis. An HPLC system (Waters, Milford, MA, USA) was used for the LC/MS/MS, and the separation was performed on an XTerra MS C18 column $(2.1 \times 30 \mathrm{~mm} 2,3.6 \mu \mathrm{m})$ with a mobile phase comprising methanol and water $(90: 10, v / v)$ at a flow rate of $0.2 \mathrm{~mL} / \mathrm{min}$. MS detection was performed using a Quattro triple quadrupole mass spectrometer equipped with an electrospray ion source (Micromass Co., Manchester, UK). The MS detection was performed with the electrospray interface maintained at $150{ }^{\circ} \mathrm{C}$ with nitrogen nebulization and with a nitrogen flow of $550 \mathrm{~L} / \mathrm{h}$. The following parameter settings were used to detect oxybutynin using the multiple-reaction monitoring (MRM) scan mode with positive ion detection: cone voltage, $32 \mathrm{~V}$; extractor, $2 \mathrm{~V}$; RF lens, 0.2 $\mathrm{V}$; source temperature, $120{ }^{\circ} \mathrm{C}$; collision cell entrance potential, $2.0 \mathrm{~V}$; collision energy, $25 \mathrm{eV}$; collision cell exit potential, $20 \mathrm{~V}$; multiplier, $650 \mathrm{~V}$; and dwell time, $0.25 \mathrm{~s}$. The following parameter settings were used to detect IS using the MRM scan mode with positive ion detection: cone voltage, $42 \mathrm{~V}$; collision energy, $30 \mathrm{eV}$; and dwell time, 0.25 s. Plasma concentrations were determined using the peak area ratio of the analyte to the IS. 


\section{Stability of CR oxybutynin tablets}

The accelerated stability study was performed for the optimized formulation OXY/CR5C4 at 40 ${ }^{\circ} \mathrm{C} / 75 \%$ relative humidity according to the $\mathrm{ICH}$ guidelines for up to 6 months. The samples were withdrawn every month and evaluated with respect to their physical appearance, drug content, and dissolution profiles. All measurements were compared with the initial results.

\section{Pharmacokinetic and statistical analyses}

The pharmacokinetic parameters of oxybutynin were calculated using the noncompartmental method in the WinNonlin software (version 5.3; Pharsight Corp., Sunnyvale, CA, USA). All data are expressed as means \pm standard deviation. A $p$-value of $<0.05$ was considered to indicate statistical significance using Student's t-test between the two means for unpaired data and Duncan's multiple range test posteriori one-way analysis of variance (ANOVA) among more than three means using the Statistical Package for the Social Sciences (SPSS) software (version 17.0; SPSS Inc., Chicago, IL, USA).

\section{RESULTS}

\section{Drug content and physical evaluation of tablets}

The drug content of the various formulations varied from 96.7 to $102.8 \%$, and the core tablet weights varied from 185 to $197 \mathrm{mg}$. The hardness of the core tablets ranged from 4.5 to $6.1 \mathrm{~kg} \cdot \mathrm{cm}^{-2}$, and the friability of the prepared core tablets ranged from 0.19 to $0.28 \%$. Thus, all physical parameters of the compressed matrices were practically within their respective limits.

\section{In vitro oxybutynin release from the $\mathrm{CR}$ tablets}

To optimize the amount of the swelling-control agent, the core formulations containing 1,5 , and $10 \%$ of the swelling-control agent were prepared as shown in Table 1. As shown in Figure 1A, the swelling-control agent enhanced the release of the drug and thus had a direct effect on drug release. Additionally, zero-order release was apparently achieved for tablets containing $1 \%$ swelling-control agent, and the formulation OXY/CR1 showed almost zero-order release and $>90 \%$ drug release at $24 \mathrm{~h}$. To assess the effect of the hydrogel-forming agent, the core formulations of oxybutynin containing 10, 20, 30 and $40 \%$ HPMC 4KM CR were prepared. The release profiles of these formulations are shown in Figure 1B. Clearly, the content of HPMC was directly related to the duration of drug release; a higher content of HPMC in the matrix caused a lower rate of release and a longer duration of zero-order release.

To modulate and optimize the drug release rate, the core formulation OXY/CR5 was further coated with various coating compositions (Table 2). The release of oxybutynin from the tablet coated with the mixture of HPMC and EC or enteric coating material is shown in Figure $1 \mathrm{C}$. In tablets with coating layers comprising HPMC and EC with weight ratios of $9: 1,8: 2$ and $7: 3$, the coating layer was completely dissolved within 1 $\mathrm{h}$; the subsequent drug release followed a zeroorder release pattern. However, the overall release rate decreased as the ratio of EC increased. On the other hand, the initial lag time of OXY/CR5 was induced by a coating layer comprising HPMC and enteric materials. After dissolution of the coating layer in the simulated intestinal fluid, the core tablet released the drug at a constant rate.

\section{In vitro drug release}

The optimized formulation OXY/CR5C4 was next subjected to in vitro drug release studies under different conditions. As shown in Figure 2A, there were no significant differences in the release profiles in the various release media, and the difference in the average cumulative release values between the groups was $<10 \%$ at each point. Additionally, release of oxybutynin from this formulation was not markedly influenced by the dissolution test method at different rotation speeds. The similarity factor value between the type 1 and 2 methods was 58.97 ( $<50.00)$. Therefore, OXY/CR5C4 was expected to show a release profile fairly independent of the $\mathrm{pH}$ and hydrodynamic conditions in the GI tract.

The release profile of OXY/CR5C4 was also compared between the commercial oxybutynin immediate-release tablet and $\mathrm{CR}$ formulation (Figure 2B). Under the simulated $\mathrm{Gl}$ condition, the release pattern of OXY/CR5C4 exhibited zero-order release for $24 \mathrm{~h}$ after 2 to $3 \mathrm{~h}$. The release pattern of Lyrinel OROS SR also exhibited a lag time because of the characteristic induction time for sufficient osmotic pressure and showed a release profile similar to that of OXY/CR5C4 (similarity factor of 71.39). 

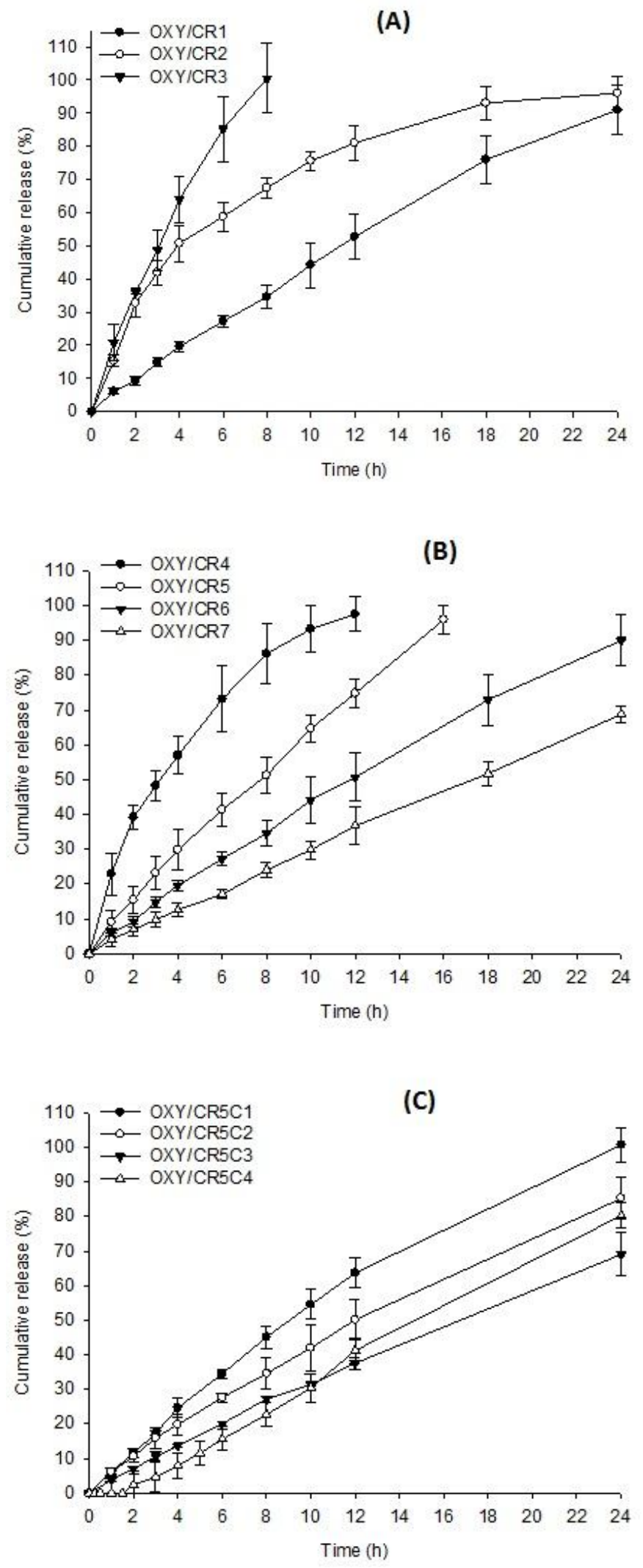

Figure 1: In vitro drug release profiles of the core tablets in SIFsp (without enzymes). (A) Effects of various amounts of croscarmellose sodium (swelling-control agent). (B) Effects of various amounts of HPMC 4KM CR. (C) Effects of various coating compositions on drug release from OXY/CR5. Data are presented as means \pm standard deviation $(n=6)$ 

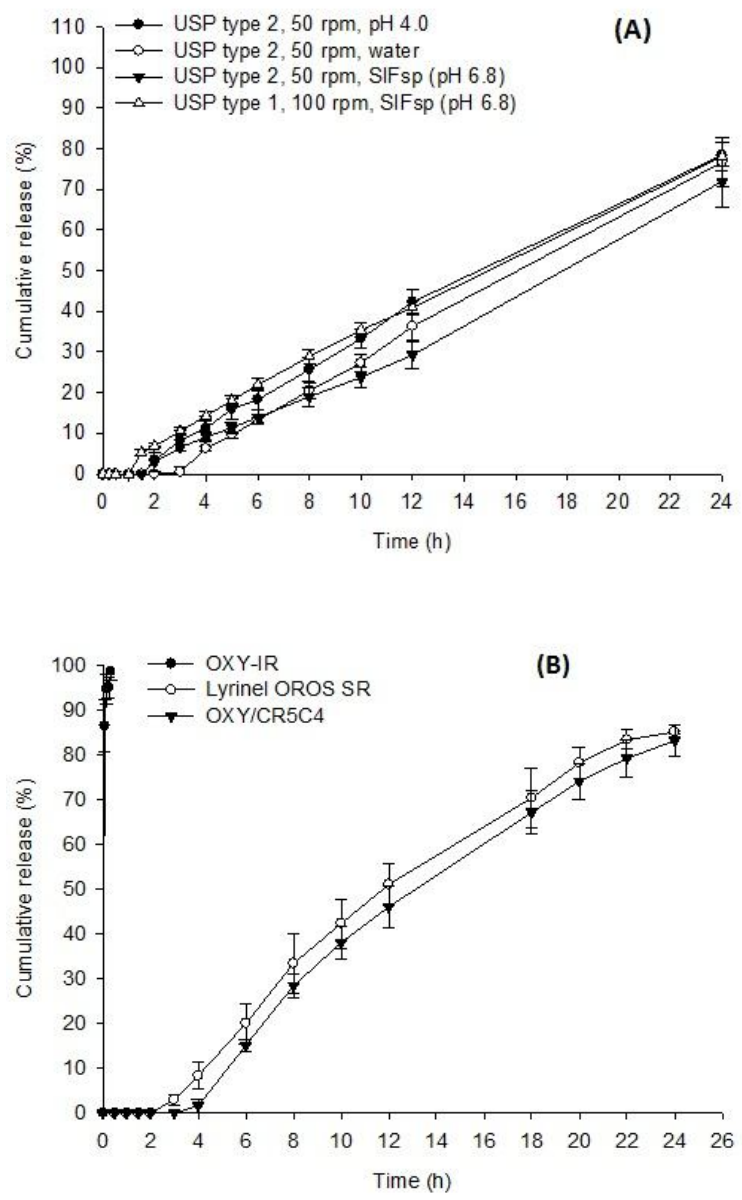

Figure 2: (A) In vitro drug release profiles of OXY/CR5C4 under various conditions. (B) Comparative in vitro drug release profiles of OXY-IR, Lyrinel OROS, and OXY/CR5C4 in SGF media (without enzymes, 0-2 h) followed by SIFsp media (without enzymes, 3-24 h). Data are presented as means \pm standard deviation $(n=6)$

\section{Pharmacokinetics of oxybutynin}

The plasma concentration-time profiles of oxybutynin after oral administration of OXY-IR, Lyrinel OROS SR, and OXY/CR5C4 in beagles are presented in Figure 3. In the fasted condition, the $C_{\max }$ values of Lyrinel OROS SR and OXY/CR5C4 were $6.47 \pm 3.73$ and $5.90 \pm 1.42$ $\mathrm{ng} / \mathrm{mL}$, respectively, and the $\mathrm{C}_{\max }$ value of OXY/CR5C4 was 3.70-fold lower than that of OXY-IR (21.84 $\pm 11.22 \mathrm{ng} / \mathrm{mL})$. The $\mathrm{AUC}_{0-24 \mathrm{~h}}$ values of Lyrinel OROS SR and OXY/CR5C4 decreased by 1.76- and 1.95-fold, respectively, compared with that of OXY-IR (198.21 \pm 96.89 $\mathrm{ng} \cdot \mathrm{h} / \mathrm{mL})$. In contrast, the $\mathrm{T}_{\max }$ value of $\mathrm{OXY/CR5C4}$ was delayed by about $3.7 \mathrm{~h}$ longer than that of OXY-IR. These results show that the drug release from OXY/CR5C4 was well controlled by erosion of the hydrogel matrix and that the released drug was continuously absorbed by the intestinal membrane. Additionally, the $\mathrm{C}_{\max }$ and $\mathrm{AUC}_{0-24 \mathrm{~h}}$ values for OXY/CR5C4 exhibited a sustained plasma drug concentration pattern comparable with that of Lyrinel OROS SR.

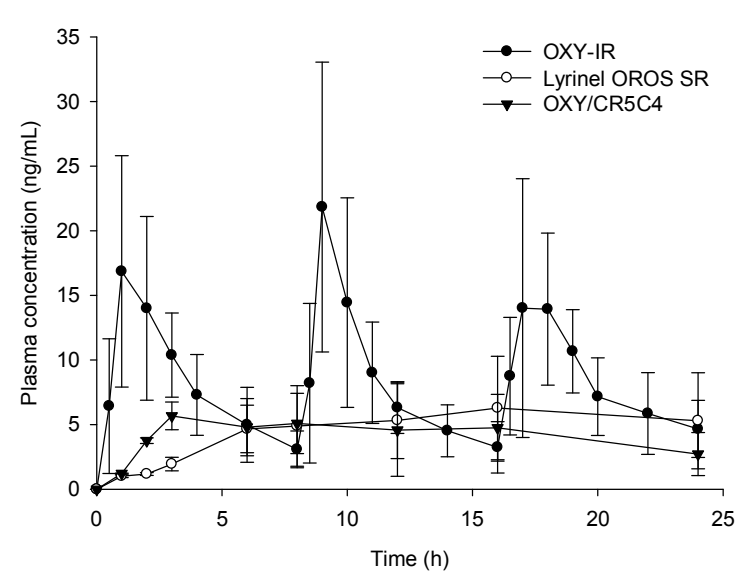

Figure 3: Comparative plasma concentration-time profiles of oxybutynin after oral administration of OXYIR (•), Lyrinel OROS SR (०), and OXY/CR5C4 ( $\nabla)$ to beagles at a dose of $15 \mathrm{mg} / \mathrm{dog}$. Data are presented as means \pm standard deviation $(n=5)$

\section{Stability of the test formulation}

The OXY/CR5C4 drug content and dissolution at $24 \mathrm{~h}$ were initially evaluated as $102.24 \pm 1.67$ and $94.06 \pm 4.90 \%$, respectively. After the 6month accelerated stability study, drug content and release were $99.63 \pm 8.34$ and $98.09 \pm 5.23$ $\%$, respectively. Therefore, the optimized formulation was stable with respect to drug content and release.

\section{DISCUSSION}

The drug release rate increased with the content of the swelling-control agent due to accelerated penetration of the medium and erosion of the matrix. The release rate was also dependent on the proportion of the hydrogel polymer present in the formulation. When the mechanism of drug release was evaluated using the KorsmeyerPeppas model $\left(M_{t} / M_{\infty}=k \times t^{n}\right)$, the $n$ values for OXY/CR5 and OXY/CR5C4 were 0.854 and 1.442 , respectively. Therefore, the overall drug release rate was controlled predominantly by erosion [6]. Additionally, the regression values for OXY/CR5 and OXY/CR5C4 were 0.9991 and 0.9862 , respectively, indicating that the drug release from these formulations followed zeroorder release for $24 \mathrm{~h}$ after the lag time. 
Oxybutynin is a tertiary amine ester and a basic drug. Therefore, uniform drug release throughout the $\mathrm{Gl}$ tract is difficult to maintain using a conventional nonionic hydrogel matrix system because the hydrophilic hydrogel matrix exhibits swelling [7]. Furthermore, erosion includes the swelling layer, diffusion layer, and erosion layer and can show zero-order drug release in a balanced state between the moving rates of these layers [8]. Therefore, the diffusional release of oxybutynin may be dominant at a gastric $\mathrm{pH}$, but the release rate would be lower at a $\mathrm{pH}$ of 6.8 because the drug particles exist in the soluble form within the matrix and so erosional release may predominate [9]. In the present study, we created oxybutynin granules with hydrophobic glyceryl behenate and embedded the granules within the erosive hydrogel matrix to form a core tablet. Finally, the core tablet was coated with a mixture of hydrophilic and enteric polymers. Therefore, drug release at a low $\mathrm{pH}$ was restricted, but the coating layer was completely dissolved when the tablet came into contact with a $\mathrm{pH}$ of 4 . The hydrogel components of the tablet then swelled and formed a gel layer on its surface, which slowly dissolved from the surface and released the granules. Finally, the drug diffused from the granules. We can thereby compensate for the decrease in the drug release area during the erosional release and make the overall drug release rate constant.

When administered orally, oxybutynin is rapidly absorbed from the GI tract. Therefore, the in vitro release profiles of OXY/CR5C4 were consistent with the plasma concentration profiles. Additionally, the $\mathrm{C}_{\max }$ and $\mathrm{AUC}$ were similar to those of the reference CR formulation, and the effective plasma concentration lasted for $24 \mathrm{~h}$. Overactive bladder is commonly more severe in the early morning; therefore, the blood concentration of the drug should be highest in the morning to ensure the greatest treatment effect [10]. This would be satisfied by modulation of the initial lag time through the coating composition. The most prevalent adverse effect, dry mouth, is also expected to be reduced as the fluctuation in the plasma level of the drug is minimized.

\section{CONCLUSION}

A hydrogel matrix-based oxybutynin CR system, designed by embedding the hydrophobic drugcontaining granules in the erodible HPMC matrix to provide constant drug release for $24 \mathrm{~h}$ is feasible. The drug release rate can be modulated by altering the content of the swelling-control agent and HPMC. Following oral administration in dogs, the optimized formulation exhibited prolonged drug absorption with minimum fluctuation, comparable to a reference product, Lyrinel OROS SR. Therefore, the optimized oxybutynin CR formulation can potentially improve patient compliance by reducing frequency of administration and side effects.

\section{ACKNOWLEDGEMENT}

This research was supported by Basic Science Research Program through the National Research Foundation of Korea (NRF) funded by Ministry of Science, ICT \& Future Planning (no. NRF-2014R1A1A1003122).

\section{REFERENCES}

1. Mehuys E, Vervaet $C$. Oral controlled release dosage forms. J Pharm Belg 2010; 2: 34-38.

2. Chapple CR. Muscarinic receptor antagonists in the treatment of overactive bladder. Urology 2000; 55 : 33-46.

3. Yarker YE, Goa KL, Fitton A. Oxybutynin. A review of its pharmacodynamic and pharmacokinetic properties, and its therapeutic use in detrusor instability. Drugs Aging 1995; 6: 243-262.

4. Goldenberg MM. An extended-release formulation of oxybutynin chloride for the treatment of overactive urinary bladder. Clin Ther 1999; 21: 634-642.

5. National Research Council of the National Academies. Guide for the care and use of laboratory animals. 8th ed. Washington DC: National Academies Press; 2011.

6. Ritger PL, Peppas NA. A simple equation for description of solute release II. Fickian and anomalous release from swellable devices. J Control Release 1987; 5: 37-42.

7. Varma MV, Kaushal AM, Garg S. Influence of microenvironmental $\mathrm{pH}$ on the gel layer behavior and release of a basic drug from various hydrophilic matrices. J Control Release 2005; 103: 499-510.

8. Colombo $P$, Bettini $R$, Peppas NA. Observation of swelling process and diffusion front position during swelling in hydroxypropyl methyl cellulose (HPMC) matrices containing a soluble drug. J Control Release 1999; 61: 83-91.

9. Hiremath PS, Saha RN. Oral matrix tablet formulations for concomitant controlled release of anti-tubercular drugs: design and in vitro evaluations. Int $J$ Pharm 2008; 362: 118-125.

10. Sathyan G, Chancellor MB, Gupta SK. Effect of OROS controlled-release delivery on the pharmacokinetics and pharmacodynamics of oxybutynin chloride. $\mathrm{Br} \mathrm{J}$ Clin Pharmacol 2001; 52: 409-417. 